\title{
Putative mechanoproteins in vertebrate cutaneous mechanoreceptors-are they at the basis of the mechanotransduction?
}

\begin{abstract}
The mammalian skin contains sensory structures (mechanoreceptors) that are responsible for different modalities of mechanosensitivity like touch, vibration and pressure sensation. These specialized sensory organs are anatomically and functionally connected to mechanosensory neurons which electrophysiologically correspond with $\mathrm{A} \beta$ fibers. The process of mechanosensitivity requires the conversion of a mechanical stimulus into an electrical signal (mechanotransduction) through the activation of ion channels that gate in response to mechanical stimuli originating actions potential potentials. The ion channels that are putatively mechanotransducer belong primarily to the families of acid-sensing ion channels, transient receptor potential channels, and Piezo2. This short review compiles the current knowledge on the occurrence of putative mechanoproteins mechanoreceptors, and therefore the involvement of these proteins on the biology of touch.
\end{abstract}

Keywords: touch, mechanoreceptors, mechanoproteins, acid-sensing ion channels, transient receptor potential channels, piezo2
Volume 4 Issue I - 2017

\author{
Cobo J, ${ }^{1,2}$ Cobo R,3 Vega JA $A^{3,4}$ \\ 'Departamento de Cirugía y Especialidades Médico Quirúrgicas, \\ Universidad de Oviedo, Spain \\ ${ }^{2}$ Instituto Asturiano de Odontología, Oviedo, Spain \\ ${ }^{3}$ Departamento de Morfología y Biología Celular, Universidad de \\ Oviedo, Spain \\ ${ }^{4}$ Facultad de Ciencias de la Salud, Universidad Autónoma de \\ Chile, Chile
}

\author{
Correspondence: José A Vega, Facultad de Medicina, \\ Universidad de Oviedo, Departamento de Morfología y Biología \\ Celular, C/ Julián Clavería, 6, 33006 Oviedo, Spain,
}

Email javega@uniovi.es

Received: March 01, 2017 | Published: August 15, 2017

\section{Introduction}

In mammals the cutaneous mechanosensitive structures that are responsible for light brush, touch, pressure sensation, stretch, and vibration are special sensory organs known collectively as cutaneous mechanoreceptors. ${ }^{1,2}$ All these modalities of mechanosensitivity are mediated by $A \beta$ and $A \alpha$ nerve fibers (the speed of action-potential propagation, myelin thickness) with low mechanical thresholds originating from intermediate- or large-sized mechanosensory neurons. ${ }^{3,4}$ The peripheral process of the mechanosensory axons contact in the skin with specialized cells like Merkel cells, or form a part of sensory organs like Meissner corpuscles, Ruffini's corpuscles, hair follicle-associated sensory nerve endings, Pacinian corpuscles. ${ }^{5-8}$

Mechanotransduction can be defined as the conversion of a mechanical stimulus into an electrical signal. The molecular mechanisms underlying this complex process still remains poorly understood, but electrophysiological studies suggest that it occurs through the activation of ion channels..$^{9-13}$ The first step of mechanotransduction occurs in the mechanoreceptors, ${ }^{14-17}$ and involves the activation of the peripheral branch of the pseudo-unipolar primary mechanosensory neurons ${ }^{14,18}$ and the sensory corpuscles connected to them. ${ }^{14-17}$

For a long time, the genesis of the action potential in mechanoreceptors was explained by the mechanical properties of the capsule and the periaxonic cells. Then, the discovery that some kinds of ion channels are gated by mechanical forces did suggest that the mystery of the genesis of the sense of touch was discovered. However, almost twenty years later the problem is unsolved. It is generally assumed that deformations in the membrane of the different cells that form the mechanoreceptors (axons, Schwann-related cells, fibroblastlike cells) $)^{7,14}$ trigger the opening of mechanosensitive ion channels that transduce mechanical energy into electrical activity. Thus, the cells forming the mechanoreceptors are thought to express ion channels activated by force or displacement to act as mechanodetectors and/ or mechanotransducers. Probably these ion channels correspond to two different categories: mechanically gated channels that act as force sensor themselves, and mechanically sensitive channels that are activated by second messengers of the true force sensors.

The present review is a compilation of the current knowledge of the relationships among mechanoreceptors and putative mechanoproteins, especially their localizations in human mechanoreceptors, and overview the sensory phenotype of mice genetically modified for these proteins.

\section{Putative mechanoproteins in the cutaneous mechanoreceptors}

To be a candidate for transducing the mechanical stimulus, ion channels must be present in the right location and must be necessary for mechanotransduction. Thus, it must be expressed and located at the site of mechanical transduction, and its blocking should block the mechanically activated conductance. Nevertheless, even if expressed properly in time and place, the putative mechaprotein could be an accessory protein for the channel and not part of the ion channel.

Members of the degenerin/epithelial sodium channels (DEG/ $\mathrm{ENaC}$ ) super family, the transient receptor potential (TRP) ion channels families, the two-pore domain potassium (K2p) channels family, and the Piezol and Piezo2 proteins are considered as putative mechanotransducer channels. ${ }^{1,9,11,19-22}$ However, only a few of them have proved to show mechanotransducer properties in vertebrates. ${ }^{21,23}$ But unfortunately, the sensory phenotypes of mice deficient for these proteins do not support always a key role in mechanotransduction. 


\section{Transient receptor potential ion channels (TRP) super family}

Members of the TRP superfamily are integral membrane proteins that function as ion channels. They consist of seven subfamilies, and at least 28 different TRP subunits have been identified in mammals. ${ }^{24}$ Nearly all TRP families have members which could be mechanosensors. ${ }^{25,26}$ In particular, TRP canonical 6 (TRPC6) is a candidate for mechanosensing which is widely distributed in mammalian tissues including DRG neurons; ${ }^{27,28}$ consistently deletion of TRPC6 causes deficits in light touch. ${ }^{29,30}$ Recently, Sexton et al. ${ }^{31}$ have demonstrated, using quadruple TRPC1, 3, 5 and 6 knockout mice that all these channels contribute to cutaneous mechanosensation in a combinatorial manner.

On the other hand, TRP vanilloid 4 (TRPV4) can works as a mechanosensor. ${ }^{32-34}$ TRPV4 was located in the axons innervating murine Meissner corpuscles, Merkel cells, penicillate nerve endings and intraepidermal terminals, but not in hair follicle palisades, ${ }^{35}$ and immunoreactivity for this protein was also detected in Merkel cells,33 or in avian mechanoreceptors. ${ }^{36}$ TRPV4 deficient mice show decreased responsiveness to sensation of noxious mechanical stimuli ${ }^{37}$ and human TRPV4 mutations cause peripheral neuropathies. ${ }^{38}$

Recently we demonstrated TRPC6 in the axon of human Meissner corpuscles (Figure 1A-1C), whereas TRPV4 was detected in the axon (Figure 1D-1F) and also in the lamellar cells; and TRPV4 and TRPC6 were co-localized in the axon..$^{39}$ TRPC6 co-operates with TRPV4 to mechanical hyperalgesia presumably as part of a mechanoreceptor signaling complex, and messenger RNAs for TRPV4 and TRPC6 are frequently co-expressed in sensory neurons ${ }^{29,40} \mathrm{~A}$ suspected role in mechanosensing has been also suggested for TRPV $2,{ }^{41}$ and TRP Ankyrin 1.9,42
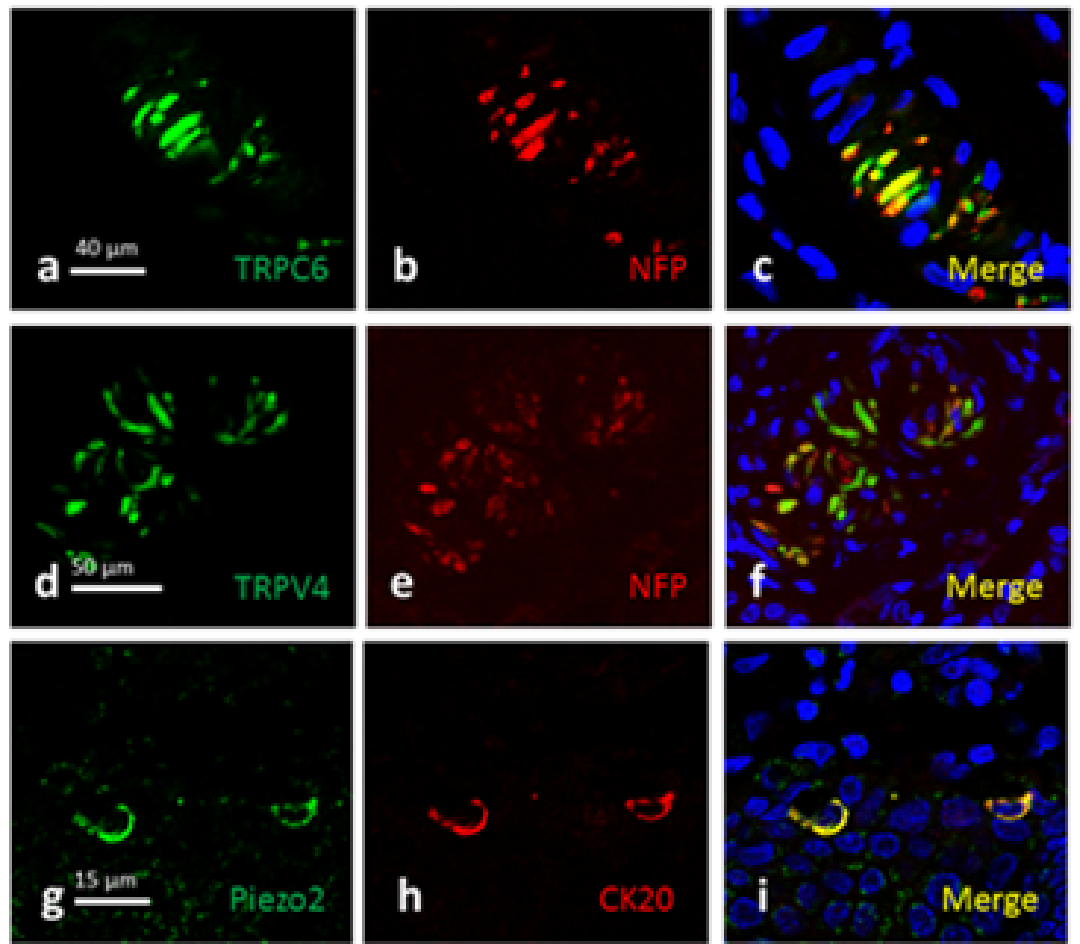

Figure I Double immunofluorescence forTRPC6 (A),TRPV4 (D) and NFP (neurofilament proteins, B,E) in human digital Meissner corpuscles. Both ion channels are localized in the axons supplying these corpuscles (C and F). The Merkel cells identified because display cytokeratin 20 (CK20, H) express Piezo2 ( $\mathrm{G}$ and I). Objective $40 x / 1.25$ Oil; pinhole airy I, XY resolution $156 \mathrm{~nm}$ and $Z$ resolution $334 \mathrm{~nm}$.

\section{Two-pore-domain potassium $(\mathrm{K}+)$ ion channels (K2P) family}

Two-pore-domain potassium $(\mathrm{K}+)$ ion channels $(\mathrm{K} 2 \mathrm{P})$ form a family within the superfamily of $\mathrm{K}+$-selective channel subunits. There are six K2P channel subfamilies, consisting of 15 distinct mammalian genes. ${ }^{43-45}$ TREK-1 and TRAAK channels belonging to this family are among the few channels for which a direct mechanical gating by membrane stretch has been shown, ${ }^{46,47}$ but is presence in mechanoreceptors has been never reported.

\section{Acid-sensing ion channels}

Acid-sensing ion channels (ASICs) are a group of $\mathrm{H}+$-gated voltage-insensitive amiloride-sensitive cation channels included in the degenerin/epithelial $\mathrm{Na}+$ channel (DEG/ENaC) superfamily. At present six ASIC proteins, subunits, encoded by four genes, have been identified: ASIC1a, ASIC1b, ASIC2a, ASIC2b, ASIC3, and $\mathrm{ASIC} 4^{48-50}$ that may function as mechanosensors or are required for mechanosensation. ${ }^{1,9,10,51}$ ASIC2 and ASIC3 were found in the axons supplying mammalian Meissner corpuscles, Merkel disks, and Pacinian corpuscles, ${ }^{52-58}$ ASIC1 was detected in human Pacinian corpuscles, ${ }^{57}$ and avian Herbst corpuscles display ASIC2 immunoreactivity. ${ }^{36}$ We have recently detected the occurrence of ASIC1 plus ASIC2, and ASIC2 alone in human cutaneous Pacinian and Meissner corpuscles, respectively, as well as in Merkel cell neurite complexes. ${ }^{59}$ In the murine Pacinian corpuscles also the inner core cells were ASIC2 positive, ${ }^{56}$ and the lamellar cells of some human Meissner and Pacinian corpuscles as well. ${ }^{59}$ 


\section{Piezo2}

Piezo2 is a vertebrate stretch-gated multipass transmembrane protein required for nonselective cationic mechanosensitive channels in mammalian cells. ${ }^{60-61}$ In the peripheral nervous system it has been detected in dorsal root ganglia neurons, ${ }^{20,62}$ Merkel discs (consisting of Merkel cells and $A \beta$-afferent nerve endings) (Figure 1g-1i) and isolated Merkel cells, ${ }^{20,63-66}$ low-threshold mechanoreceptors that innervate both hairy and glabrous skin including Meissner corpuscles and lanceolate nerve endings. ${ }^{62}$ Consistently animals deficient in Piezo2 show an almost complete deficit in light-touch sensation and proprioception without affecting other somatosensory functions. ${ }^{62,66} \mathrm{In}$ human patients carrying mutations in Piezo2 show a selective loss of touch perception and have profoundly decreased proprioception. ${ }^{67,68}$

\section{Only mechanoproteins?}

In summarizing the current knowledge, the ion channels can be gated by three mechanisms:

A. They can be opened by modifications of the cell membrane in the vicinity of the channels;

B. The intra- and extra-cytoplasmic domains of ion channels are bound to the proteins of the cytoskeleton and the extracellular matrix, respectively, and the tension of these proteins can produce the opening of ion channels; and

C. That the channels are coupled to mechanosensory proteins through intermediaries of signaling. ${ }^{9}$ Therefore, any of the three previous theories should be at the basis of mechanotransduction in the mechanoreceptors. The involvement of these putative mechanoproteins in mechanosensing is now universally accepted, and cannot explain alone the compels mechanotransduction process. In fact, the disruption of cytoskeletal proteins in cultured sensory neurons results in the disappearance of the action potential induced by mechanical stimulation. Likely when ion channels like TRP or ASIC are blocked the mechanical stimulation of cells results in no changes in the action potential with respect to the cells without blocking. These experiments clearly suggest that there is something more than the mechanoproteins in the genesis of the mechanotransduction and that sensory nerve terminals have a specific mechanosensitive response that is related to cell architecture..$^{69,70}$

\section{Acknowledgements}

None.

\section{Conflict of interest}

Author declares that there is no conflict of interest.

\section{References}

1. Gillespie PG, Walker RG. Molecular basis of mechanosensory transduction. Nature. 2001;413(6852):194-202.

2. Zimmerman A, Bai L, Ginty DD. The gentle touch receptors of mammalian skin. Science. 2014;346(6212):950-954.

3. Smith ES, Lewin GR. Nociceptors: a phylogenetic view. J Comp Physiol A Neuroethol Sens Neural Behav Physiol. 2009;195(12):1089-1106.

4. Abraira VE, Ginty DD. The sensory neurons of touch. Neuron. 2013;79(4):618-639.

5. Munger BL, Ide C. The structure and function of cutaneous sensory receptors. Arch Histol Cytol. 1988;51(1):1-34.
6. Zelena J. Nerves and mechanoreceptors. UK: Chapman \& Hall; 1994. $356 \mathrm{p}$.

7. Vega JA, Haro JJ, Del Valle ME. Immunohistochemistry of human cutaneous Meissner and pacinian corpuscles. Microsc Res Tech. 1996;34(4):351-361.

8. Rice FL, Albrecht PJ. Cutaneous Mechanisms of Tactile Perception: Morphological and Chemical Organization of the Innervation to the Skin. In: Allan I Basbaum, editors. The Senses: A Comprehensive Reference, Somato sensation. San Diego: Academic Press; 2008:1-32.

9. Lumpkin EA, Caterina MJ. Mechanisms of sensory transduction in the skin. Nature. 2007;445(7130):858-865.

10. Tsunozaki M, Bautista DM. Mammalian somatosensory mechanotransduction. Curr Opin Neurobiol. 2009;19(4):362-369.

11. Lumpkin EA, Marshall KL, Nelson AM. The cell biology of touch. $J$ Cell Biol. 2010;191(2):237-248.

12. GuY, Gu C. Physiological and pathological functions of mechanosensitive ion channels. Mol Neurobiol. 2014;50(2):339-347.

13. Paluch EK, Nelson CM, Biais N, et al. Mechanotransduction: use the force(s). BMC Biol. 2015;13:47.

14. Vega JA, García Suárez O, Montaño JA, et al. The Meissner and Pacinian sensory corpuscles revisited new data from the last decade. Microsc Res Tech. 2009;72(4):299-309.

15. McGlone F, Reilly D. The cutaneous sensory system. Neurosci Biobehav Rev. 2010;34(2):148-159.

16. Roudaut Y, Lonigro A, Coste B, et al. Touch sense: functional organization and molecular determinants of mechanosensitive receptors. Channels (Austin). 2012;6(4):234-245.

17. Fleming MS, Luo W. The anatomy, function, and development of mammalian A $\beta$ low-threshold mechanoreceptors. Front Biol (Beijing). 2013:8(4)

18. Li L, Rutlin M, Abraira VE, et al. The functional organization of cutaneous low-threshold mechanosensory neurons. Cell. 2011;147(7):1615-1627.

19. Arnadottir J, Chalfie M. Eukaryotic mechanosensitive channels. Annu Rev Biophys. 2010;39:111-137.

20. Coste B, Mathur J, Schmidt M, et al. Piezo1 and Piezo2 are essential components of distinct mechanically activated cation channels. Science. 2010;330(6000):55-60.

21. Ranade SS, Syeda R, Patapoutian A. Mechanically activated ion channels. Neuron. 2015;87(6):1162-1179.

22. Sharif Naeini R. Contribution of mechanosensitive ion channels to somatosensation. Prog Mol Biol Transl Sci. 2015;131:53-71.

23. Delmas P, Coste B. Mechano-gated ion channels in sensory systems. Cell. 2013;155(2):278-284.

24. Clapham DE, Julius D, Montell C, et al. International union of pharmacology. XLIX. Nomenclature and structure-function relationships of transient receptor potential channels. Pharmacol Rev. 2005;57(4):427-450.

25. Gottlieb P, Folgering J, Maroto R, et al. Revisiting TRPC1 and TRPC6 mechanosensitivity. Pflugers Arch. 2008;455(6):1097-1103.

26. Patel A, Sharif Naeini R, Folgering JR, et al. Canonical TRP channels and mechanotransduction: from physiology to disease states. Pflugers Arch. 2010;460(3):571-581.

27. Dietrich A, Gudermann T. TRPC6. Handb Exp Pharmacol. 2007; 179:125-141.

28. Dietrich A, Gudermann T. TRPC6: physiological function and pathophysiological relevance. Handb Exp Pharmacol. 2014;222:157-188. 
29. Alessandri Haber N, Dina OA, Chen X, et al. TRPC1 and TRPC6 channels cooperate with TRPV4 to mediate mechanical hyperalgesia and nociceptor sensitization. J Neurosci. 2009;29(19):6217-6228.

30. Quick K, Zhao J, Eijkelkamp N, et al. TRPC3 and TRPC6 are essentia for normal mechanotransduction in subsets of sensory neurons and cochlear hair cells. Open Biol. 2012;2(5):120068.

31. Sexton JE, Desmonds T, Quick K, et al. The contribution of TRPC1, TRPC3, TRPC5 and TRPC6 to touch and hearing. Neurosci Lett. 2016;610:36-42.

32. Liedtke W. TRPV4 plays an evolutionary conserved role in the transduction of osmotic and mechanical stimuli in live animals. $J$ Physiol. 2005;567(pt 1):53-58.

33. Liedtke W, Choe Y, Martí Renom MA, et al. Vanilloid receptor-related osmotically activated channel (VR-OAC), a candidate vertebrate osmoreceptor. Cell. 2000;103(3):525-535.

34. Garcia Elias A, Mrkonjić S, Jung C, et al. The TRPV4 channel. Handb Exp Pharmacol. 2014;222:293-319.

35. Suzuki M, Watanabe Y, Oyama Y, et al. Localization of mechanosensitive channel TRPV4 in mouse skin. Neurosci Lett. 2003;353(3):189-192.

36. Cabo R, Gálvez A, Laurà R, et al. Immunohistochemical detection of the putative mechanoproteins ASIC2 and TRPV4 in avian herbst sensory corpuscles. Anat Rec (Hoboken). 2013;296(1):117-122.

37. Liedtke W, Friedman JM. Abnormal osmotic regulation in trpv4-/- mice. Proc Natl Acad Sci USA. 2003;100(23):13698-13703.

38. Evangelista T, Bansagi B, Pyle A, et al. Phenotypic variability of TRPV4 related neuropathies. Neuromuscul Disord. 2015;25(6):516-521.

39. Alonso González P, Cabo R, San José I, et al. Human digital Meissner corpuscles display immunoreactivity for the multifunctional ion channels trpc6 and trpv4. Anat Rec (Hoboken). 2016;300(6):1022-1031.

40. Alessandri Haber N, Dina OA, Joseph EK, et al. Interaction of transient receptor potential vanilloid 4, integrin, and SRC tyrosine kinase in mechanical hyperalgesia. J Neurosci. 2008;28(5):1046-1057.

41. Muraki K, Iwata Y, Katanosaka Y, et al. TRPV2 is a component of osmotically sensitive cation channels in murine aortic myocytes. Circ Res. 2003;93(9):829-838.

42. Kwan KY, Glazer JM, Corey DP, et al. TRPA1 modulates mechanotransduction in cutaneous sensory neurons. $J$ Neurosci. 2009;29(15):4808-4819.

43. Goldstein SA, Bayliss DA, Kim D, et al. International union of pharmacology. LV. Nomenclature and molecular relationships of two-P potassium channels. Pharmacol Rev. 2005;57(4):527-540.

44. Duprat F, Lauritzen I, Patel A, et al. The TASK background K2P channels chemo- and nutrient sensors. Trends Neurosci. 2007;30(11):573-580.

45. Sabbadinia M, Yost CS. Molecular biology of background K channels Insights from K2P Knockout Mice. J Mol Biol. 2009;385(5):1331-1344.

46. Maingret $\mathrm{F}$, Fosset $\mathrm{M}$, Lesage $\mathrm{F}$, et al. TRAAK is a mammalian neurona mechano-gated K+ channel. J Biol Chem. 1999;274(3):1381-1387.

47. Maingret F, Patel AJ, Lesage F, et al. Mechano- or acid stimulation, two interactive modes of activation of the TREK-1 potassium channel. J Biol Chem. 1999;274(38):26691-26696.

48. Holzer P. Acid-sensitive ion channels and receptors. Handb Exp Pharmacol. 2009;194:283-332.

49. Holzer P. Acid-sensing by visceral afferent neurones. Acta Physiol. 2011;201(1):63-75

50. Sherwood TW, Frey EN, Askwith CC. Structure and activity of the acidsensing ion channels. Am J Physiol Cell Physiol. 2012;303(7):C699C710.
51. Chen CC, Wong CW. Neurosensory mechanotransduction through acidsensing ion channels. J Cell Mol Med. 2013;17(3):337-349.

52. Price MP, Lewin GR, McIlwrath SL, et al. The mammalian sodium channel $\mathrm{BNC1}$ is required for normal touch sensation. Nature. 2000;407(6807):1007-1011.

53. Price MP, McIlwrath SL, Xie J, et al. The DRASIC cation channel contributes to the detection of cutaneous touch and acid stimuli in mice. Neuron. 2001;32(6):1071-1083.

54. Garcia Añoveros J, Samad T, Zuvela Jelaska L. Transport and localization of the $\mathrm{DEG} / \mathrm{ENaC}$ ion channel $\mathrm{BNaC} 1 \alpha$ to periphera mechanosensory terminals of dorsal root ganglia neurons. $J$ Neurosci. 2001;21(8):2678-2686.

55. Duggan A, Garcia Añoveros J, Corey DP. The PDZ domain protein PICK1 and the sodium channel $\mathrm{BNaC1}$ interact and localize at mechanosensory terminals of dorsal root ganglion neurons and dendrites of central neurons. J Biol Chem. 2002;277(7):5203-5208.

56. Montaño JA, Calavia MG, García Suárez O, et al. The expression of $\mathrm{ENa}(+) \mathrm{C}$ and $\mathrm{ASIC} 2$ proteins in Pacinian corpuscles is differently regulated by TrkB and its ligands BDNF and NT-4. Neurosci Lett. 2009;463(2):114-118

57. Calavia MG, Montaño JA, García Suárez O, et al. Differential localization of acid-sensing ion channels 1 and 2 in human cutaneus pacinian corpuscles. Cell Mol Neurobiol. 2010;30(6):841-884.

58. Cabo R, Gálvez MA, San José I, et al. Immunohistochemical localization of acid-sensing ion channel 2 (ASIC2) in cutaneous Meissner and Pacinian corpuscles of Macaca fascicularis. Neurosci Lett. 2012;516(2):197-201.

59. Cabo R,Alonso P, ViñaE, etal.ASIC2 is present in human mechanosensory neurons of the dorsal root ganglia and in mechanoreceptors of the glabrous skin. Histochem Cell Biol. 2015;143(3):267-276.

60. Honoré E, Martins JR, Penton D, et al. The piezo mechanosensitive ion channels: may the force be with you! Rev Physiol Biochem Pharmacol. 2015;169:25-41.

61. Nakatani M, Maksimovic S, Baba Y, et al. Mechanotransduction in epidermal Merkel cells. Pflugers Arch. 2015;467(1):101-108.

62. Ranade SS, Woo SH, Dubin AE, et al. Piezo2 is the major transducer of mechanical forces for touch sensation in mice. Nature. 2014;516(7529):121-125.

63. Ikeda $\mathrm{R}$, Cha M, Ling J, et al. Merkel cells transduce and encode tactile stimuli to drive A $\beta$-afferent impulses. Cell. 2014;157(3):664-675.

64. Woo SH, Ranade S, Weyer AD, et al. Piezo2 is required for Merkel-cell mechanotransduction. Nature. 2014;509(7502):622-626.

65. Woo SH, Lukacs V, de Nooij JC, et al. Piezo2 is the principal mechanotransduction channel for proprioception. Nat Neurosci. 2015;18(12):1756-1762.

66. Woo SH, Lumpkin EA, Patapoutian A. Merkel cells and neurons keep in touch. Trends Cell Biol. 2015;25(2):74-81.

67. Chesler AT, Szczot M, Bharucha Goebel D, et al. The Role of PIEZO2 in Human Mechanosensation. N Engl J Med. 2016;375(14):1355-1364.

68. Mahmud AA, Nahid NA, Nassif C, et al. Loss of the proprioception and touch sensation channel PIEZO2 in siblings with a progressive form of contractures. Clin Genet. 2016;91(3):470-475.

69. Lin YW, Cheng CM, Leduc PR, et al. Understanding sensory nerve mechanotransduction through localized elastomeric matrix control. PLoS One. 2009;4(1):e4293.

70. Sachs F. Stretch-activated ion channels: what are they? Physiology (Bethesda). 2010;25(1):50-56 